\title{
PLEURAL MESOTHELIOMA: CASE-REPORT OF UNCOMMON OCCUPATIONAL ASBESTOS EXPOSURE IN A SMALL FURNITURE INDUSTRY
}

\section{ENRICO ODDONE and MARCELLO IMBRIANI}

University of Pavia, Pavia, Italy

Department of Public Health, Experimental and Forensic Medicine, Occupational Medicine Unit "Salvatore Maugeri"

\begin{abstract}
The relationship between asbestos exposure and malignant mesothelioma is no longer disputed, although it is not always easy to trace past occupational exposure. This report describes a case of uncommon asbestos exposure of a small furniture industry worker, who subsequently died of pleural malignant mesothelioma, to stress the crucial importance of a full reconstruction of the occupational history, both for legal and compensation purposes. Sarcomatoid pleural mesothelioma was diagnosed in a 70-year-old man, who was previously employed as a carpenter in a small furniture industry. He worked for about 6 years in the small factory, was exposed to asbestos during the assembly of the furniture inspired by classical architecture, in which asbestos cement tubes were used to reproduce classical columns. During this production process no specific work safety measures were applied, nor masks or local aspirators. No extra-professional exposure to asbestos was identified. This mesothelioma case was investigated by the Public Prosecutor's assignment that commissioned expert evidence on the legal accountability for the disease. Despite its uncommon expositive circumstance, the length of latency (about 30 years), the duration of exposure, the clinical and histochemical features are all consistent with literature evidence, accounting for the occupational origin of this malignancy.
\end{abstract}

Key words:

Occupational exposure, Asbestos, Furniture industry, Carpenter, Mesothelioma, Occupational medicine

\section{INTRODUCTION}

To date, the causal relationship between asbestos exposure and malignant mesothelioma (MM) is no longer disputed [1]. Occupational exposure, especially among men, could account for the large majority of MM cases, with an attributable risk varying between $30-80 \%$ across different populations [2,3]. When para-occupational exposure (e.g., living near an asbestos factory or handling clothes contaminated with asbestos, due to occupational exposure) are added to the occupational ones, the attributable factor can rise to $>95 \%$ [4].
In Italy, among the incident MM cases in the period 19932004, occupational asbestos exposure was observed in $69.3 \%$, while para-occupational exposure was observed in $9.1 \%$. These results amount to $81 \%$ of MM cases with occupational exposure when only men were considered [5]. Geographical variations in the mesotheliomas burden are often strictly related to the distribution of asbestos-using industries in the past [5-8], thus a substantial part of non-occupational MM cases could be explained by such environmental exposure [9].

Received: February 2, 2015. Accepted: June 24, 2015.

Corresponding author: E. Oddone, University of Pavia, Department of Public Health, Experimental and Forensic Medicine, Occupational Medicine Unit "Salvatore Maugeri," Via Severino Boezio 24, 27100 Pavia, Italy (e-mail: enrico.oddone@unipv.it). 
Despite that, it is not always easy to detect past asbestos exposure, especially in work activities, in which asbestos use is unexpected, that led to the classification of exposure to this mineral fiber of several MM cases as "unknown."

Here we describe the case of a carpenter occupationally exposed to asbestos during his employment in a small furniture industry. Although carpenters have been frequently observed to be an occupational group at high risk of MM $[10,11]$, the evidence generally regards large groups of construction workers [12,13], or carpenters employed in the building industry, electricity supply or manufacture of products containing asbestos [14]. Nevertheless, some recent studies indicate carpenters as workers employed in industries, in which asbestos exposure could be considered secondary and somehow unexpected $[15,16]$. Moreover, the furniture industry is not considered as a traditional branch, in which asbestos exposure may occur [17], making it more difficult to attribute the disease to professional exposure. Thus, highlighting this possible asbestos exposure is essential, especially when we deal with small industries or self-employed workers.

Following these considerations, the aim of this case-report is to highlight unexpected and peculiar asbestos exposure, to stress the importance of a comprehensive, punctual and accurate reconstruction of the work history when dealing with MM cases, both for legal purposes and for compensation.

\section{CASE DESCRIPTION}

Pleural mesothelioma was diagnosed in a carpenter, formerly employed in a small furniture factory. No other asbestosrelated disease was present at hospital admittance for dry cough and severe dyspnoea, while a patient suffered from diabetes, dyslipidemia, hypertension and Parkinson disease. The definite diagnosis of mesothelioma was made in 2012 on the basis of histological and immune-histochemical features. In particular, the patient had a sarcomatoid malignant mesothelioma at the right pleura, with a histochemical pattern showing positive vimentin and calretinin results, and negative carcinoembryonic antigen (CEA). Also due to the presence of a significant comorbidity that contraindicated an aggressive therapy, the worker died in the same year, 6 months diagnosis following.

The patient had worked as a carpenter in several small furniture companies from 1960 to 2001. No exposure to asbestos has been traced in these companies, except for one in which the patient worked from 1982 to 1989, for a total number of 74 months. His job consisted in the assembly of several types of furniture (e.g., bookcases, shelves, tables, coat hangers, etc.) of a particular patented line inspired by classical architecture. Therefore, to reproduce classical columns, asbestos-cement tubes were used. To be more specific, the patient had to cut asbestos tubes with a common circular saw to obtain the needed length before the assembly and then to drill the same tubes or to insert anchors. All these tasks exposed the patient to the inhalation of dusts containing asbestos fibers.

During this production process, no specific work safety measures were applied, nor masks or local aspirators. Moreover, despite the use of materials containing asbestos, no measurement of airborne fibers concentration is available for this factory and, probably, none was carried out before it had closed down. Furthermore, no information is available concerning the type of asbestos fiber involved in this case, however, it is likely to be a mixture of chrysotile and crocidolite, commonly used in Italy for asbestos cement products [18].

No extra-professional exposure to asbestos was identified. Direct environmental contact seemed not to be an issue of particular concern, given that the patient had the same environmental exposure as the general population. Paraoccupational exposure (due to hobbies or similar) have not been tracked, and likely none was present.

The analysis of the job history was considered consistent with occupational exposure to asbestos due to the worker's specific job task, also considering the long time interval 
(about 30 years) elapsed between the employment start and the diagnosis.

\section{DISCUSSION AND CONCLUSIONS}

Carpenters are often considered as an occupational category at high risk of asbestos exposure and, consequently, at high risk of MM. Conversely, scarce and not recent evidence is present for the furniture industry, in which asbestos exposure is sometimes neglected or misclassified $[17,19]$. These issues could limit the recognition of these MM cases as occupational diseases and the relative claim for compensation [20].

When asbestos exposure has occurred in tasks regarding self-employed workers, or groups of few workers, or in small factories with a few laborers (as in this case), it is difficult to retrospectively reconstruct the occupational history and to assess the risk due to asbestos. Despite these issues, in our opinion, it is crucial to fully investigate the MM cases, both for legal and compensation purposes. This MM case was investigated by the Public Prosecutor's assignment that commissioned expert evidence on the legal accountability for the disease. Thus, clinical records, an occupational assessment, an interview with the patient, his relatives and workmates were provided directly from the judicial authority. These documents, along with the reconstruction provided independently by the Italian Mesothelioma Registry, an "active registry" devoted exclusively to this disease [11], allowed us to classify this case as an occupational one, despite its uncommon expositive circumstance.

In particular, the length of latency (about 30 years), the duration of exposure (about 6 years), the clinical onset of the disease and the histochemical features, are consistent with the literature evidence. Indeed, a significant increase in mesothelioma risk has been observed also for short lengths of exposure of about 5 years [21].

No direct information is available on the asbestos fiber type involved in this exposure. As shown by studies regarding Italian asbestos-cement factories, both crocidolite and chrysotile were used to produce tubes, in a varying percent of the dry weight [18]. Thus, it is probable that the patient was exposed to both.

This report provides further proofs of the importance of a comprehensive reconstruction of occupational exposure, especially in those MM cases, in which the link with a productive branch known to be asbestos-exposing is not clearly evident.

\section{ACKNOWLEDGMENTS}

The Authors would like to thank Dr. Maria Letizia Mocciaro, Public Prosecutor of Milan (Italy), for the permission to publish, and Dr. Maurizio Ghezzi, police official, for his information support.

\section{REFERENCES}

1. World Health Organization, International Agency for Research on Cancer. IARC monographs on the evaluation of carcinogenic risks to humans. Vol. 100: Review of human carcinogens. Lyon: The Agency; 2012.

2. Albin M, Magnani C, Krstev S, Rapiti E, Shefer I. Asbestos and cancer: An overview of current trends in Europe. Environ Health Perspect. 1999 May;107 Suppl 2:289-98.

3. Whitwell F, Rawcliffe RM. Diffuse malignant pleural mesothelioma and asbestos exposure. Thorax. 1971 Jan;26(1): 6-22, http://dx.doi.org/10.1136/thx.26.1.6.

4. Rushton L, Bagga S, Bevan R, Brown TP, Cherrie JW, Holmes P, et al. Occupation and cancer in Britain. Br J Cancer. 2010 Apr 27;102(9):1428-37, http://dx.doi.org/10.1038/sj. bjc.6605637.

5. Marinaccio A, Binazzi A, Marzio DD, Scarselli A, Verardo M, Mirabelli D, et al. Pleural malignant mesothelioma epidemic: Incidence, modalities of asbestos exposure and occupations involved from the Italian National Register. Int J Cancer. 2012 May 1;130(9):2146-54, http://dx.doi.org/10.1002/ ijc.26229.

6. Fazzo L, de Santis M, Minelli G, Bruno C, Zona A, Marinaccio A, et al. Pleural mesothelioma mortality and asbestos 
exposure mapping in Italy. Am J Ind Med. 2012 Jan;55(1): 11-24, http://dx.doi.org/10.1002/ajim.21015.

7. Fazzo L, Minelli G, Santis MD, Bruno C, Zona A, Marinaccio $\mathrm{A}$, et al. Mesothelioma mortality surveillance and asbestos exposure tracking in Italy. Ann Ist Super Sanita. 2012;48(3):300-10, http://dx.doi.org/10.4415/ANN_12_03_11.

8. Mensi C, Riboldi L, de Matteis S, Bertazzi PA, Consonni D. Impact of an asbestos cement factory on mesothelioma incidence: Global assessment of effects of occupational, familial, and environmental exposure. Environ Int. 2015 Jan;74:191-9, http://dx.doi.org/10.1016/j.envint.2014.10.016.

9. Mirabelli D, Cavone D, Merler E, Gennaro V, Romanelli A, Mensi $\mathrm{C}$, et al. Non-occupational exposure to asbestos and malignant mesothelioma in the Italian National Registry of Mesotheliomas. Occup Environ Med. 2010 Nov;67(11): 792-4, http://dx.doi.org/10.1136/oem.2009.047019.

10. Rake C, Gilham C, Hatch J, Darnton A, Hodgson J, Peto J. Occupational, domestic and environmental mesothelioma risks in the British population: A case-control study. Br J Cancer. 2009 Apr 7;100(7):1175-83, http://dx.doi. org/10.1038/sj.bjc.6604879.

11. Nesti M, Marinaccio A, Gennaro V, Gorini G, Mirabelli D, Mensi C, et al. Epidemiologic surveillance for primary prevention of malignant mesothelioma: The Italian experience. Med Lav. 2005 Jul-Aug;96(4):338-46.

12. Stocks SJ, Turner S, McNamee R, Carder M, Hussey L, Agius RM. Occupation and work-related ill-health in UK construction workers. Occup Med (Lond). 2011 Sept;61(6): 407-15, http://dx.doi.org/10.1093/occmed/kqr075.

13. McDonald JC, Edwards CW, Gibbs AR, Lloyd HM, Pooley FD, Ross DJ, et al. Case-referent survey of young adults with mesothelioma: II. Occupational analyses. Ann Occup Hyg. 2001 Oct;45(7):519-23, http://dx.doi.org/10.1093/ annhyg/45.7.519.
14. Hannaford-Turner K, Elder D, Sim MR, Abramson MJ, Johnson AR, Yates DH. Surveillance of Australian workplace Based Respiratory Events (SABRE) in New South Wales. Occup Med (Lond). 2010 Aug;60(5):376-82, http:// dx.doi.org/10.1093/occmed/kqq011.

15. McElvenny DM, Darnton AJ, Price MJ, Hodgson JT. Mesothelioma mortality in Great Britain from 1968 to 2001. Occup Med (Lond). 2005 Mar;55(2):79-87, http://dx.doi. org/10.1093/occmed/kqi034.

16. Montomoli L, Spisso M, Romeo R, Spina D, Ghiribelli C, Sartorelli P. [Work related mesothelioma: Analysis of cases discovered at the Section for Occupational Medicine and Toxicology of Siena University during the years 2000-2007]. G Ital Med Lav Ergon. 2007 Jul-Sep;29 Suppl 3:332-3. Italian.

17. Minder CE, Vader JP. Malignant pleural mesothelioma among Swiss furniture workers. A new high-risk group. Scand J Work Environ Health. 1988 Aug;14(4):252-6, http://dx.doi.org/10.5271/sjweh.1924.

18. Oddone E, Ferrante D, Cena T, Tunesi S, Amendola P, Magnani C. [Asbestos cement factory in Broni (Pavia, Italy): A mortality study]. Med Lav. 2014;105(1):15-29. Italian.

19. Merler E, Ricci P. Re: "Malignant pleural mesothelioma among Swiss furniture workers: A new high-risk group" by Minder CE, Vader JP. Scand J Work Environ Health. 1988;14:252-6. Scand J Work Environ Health. 1989 Dec;15(6):439-40, http://dx.doi.org/10.5271/sjweh.1828.

20. Nay SY. Asbestos in Belgium: Use and abuse. Int J Occup Environ Health. 2003;9(3):287-93, http://dx.doi.org/10. 1179/oeh.2003.9.3.287.

21. Berry G, Pooley F, Gibbs A, Harris JM, McDonald JC. Lung fiber burden in the Nottingham gas mask cohort. Inhal Toxicol. 2009;21(2):168-72, http://dx.doi.org/10.1080/ 08958370802291304.

This work is available in Open Access model and licensed under a Creative Commons Attribution-NonCommercial 3.0 Poland License - http://creativecommons.org/ licenses/by-nc/3.0/pl/deed.en. 